\title{
Variación lingüística y norma en la enseñanza del español como lengua extranjera
}

\author{
HUMBERTO HERNÁNDEZ \\ Universidad de La Laguna \\ hhdezh@ull.edu.es
}

\begin{abstract}
Resumen
Uno de los asuntos más debatidos en el ámbito de la enseñanza del español para nativos, pero, sobre todo, para extranjeros es el de cuál debe ser el modelo o la norma en que habrá de basarse esa enseñanza. Suele optarse por elegir como norma prototípica la castellana del centro norte peninsular por una rutina que viene dada por la tradición o por la errónea creencia de que de las grandes modalidades del español esta es la más culta, la más correcta y la más general: el seseo, en el plano fónico, o la ausencia del pronombre vosotros en lo gramatical suelen considerarse rasgos dialectales, entendiendo como tales aquellas características que se alejan del modelo que previamente se ha fijado como el ejemplar. En este trabajo expondremos las razones por las que todas estas ideas no son del todo ciertas y que en ocasiones (en otros contextos y situaciones) puede ocurrir que la norma seseante o la que prefiere el ustedes sea la preferida por culta, por correcta y por general. Proponemos, pues, que para una enseñanza de la lengua más ajustada a la realidad se acuda a otros parámetros; propuesta que supone la exigencia de que el profesor o la profesora que enseñe español deberá poseer una sólida formación en la estructura general de la lengua y en las características de sus principales modalidades, características que de una manera sucinta se ofrecen en este trabajo.
\end{abstract}

\section{Palabras clave}

Enseñanza de la lengua; español lengua extranjera; variación lingüística. 


\title{
Linguistic Variation versus Normativity in the Teaching of Spanish as Foreign Language
}

\begin{abstract}
One of the most debated issues in the field of teaching Spanish to natives, and in particular to foreigners, is which model or norm should be chosen. It is often thought that Castillian Spanish should be the prototypical norm to be taught for reasons that have to do with tradition, or due to a mistaken belief that, among other important Spanish language varieties, the one spoken by cultured people living in the centre and northern Spain is the best, the most correct and the most generally used. Seseo, at the phonetic level, or the absence of the pronoun vosotros, at the grammatical level, are often considered to be dialect features, that is, features which deviate from the model previously set as standard. In this paper, we aim to contribute to a better understanding of this matter, since there are occasions (contexts and situations) which favour seseo or the use of ustedes for similar reasons as above. A more realistic perspective of teaching the language entails that teachers must have a solid knowledge of the general structure of Spanish as well of its main varieties, which we present here in a concise manner.
\end{abstract}

\section{Keywords}

Language teaching; Spanish foreign language; linguistic variation.

Recibido el 10/02/2020

Aceptado el 15/06/2020 


\section{Introducción}

Es posible que por el título de este artículo pudiera deducirse que su objetivo es de tipo reivindicativo, esto es, defender una postura, un método o una perspectiva frente a otras por considerarlas equivocadas o erróneas; antes bien, lejos de censuras o reprobaciones, aspiramos a conseguir mayor objetividad y menos dogmatismos como los que solo se justifican por razones atribuibles a la ignorancia. Y no voy a ocultar que el principal motivo de estas reflexiones es el de haber constatado que por más que desde las disciplinas lingüísticas y desde la didáctica practicada con rigor se hayan erradicado viejos prejuicios ante la realidad de las lenguas («no hay lengua pequeña», decía Steiner [2001]) todavía haya quien adopte actitudes que contradicen el más elemental de los principios desde la perspectiva científica y que ofenden, desde un punto de vista sociocultural, a comunidades que observan cómo se infravalora el más preciado de su patrimonio cultural: su lengua, expresada en su correspondiente modalidad dialectal. Y todo esto es posible detectarlo analizando métodos y propuestas relacionados con la enseñanza de la lengua, sobre todo si esta enseñanza está dirigida a estudiantes extranjeros, pues cuando se trata de nativos las posibles deficiencias que pudieran surgir se atenúan por el natural conocimiento del hablante. El profesor que habrá de enseñar lengua a un aprendiz extranjero tendrá que decidir qué modalidad, qué norma, qué estándar habrá de ser el punto de partida para todo el proceso posterior de enseñanza / aprendizaje.

Y es aquí cuando se plantean los problemas, pues no parece haber consenso acerca de qué modalidad, qué norma o qué estándar habrá de enseñarse: ¿la norma académica?, ¿la castellana?, ¿la más general?, ¿un español neutro?, ¿el español estándar? Claro que no todo el mundo entiende lo mismo sobre estas denominaciones, y más que detenernos en comentar lo que suele entenderse por español académico, castellano o estándar sería mejor ir en busca de respuestas razonables, porque desde una perspectiva científica no queda del todo claro, aunque podemos adelantar que lo frecuente es afirmar que lo ortodoxo didácticamente sería reconocer que la norma castellana (la de modalidad septentrional del español) constituiría el modelo indiscutible, el prototipo, la mejor y la de mayor prestigio de entre las muchas normas cultas que existen en todo el ámbito del idioma; ocho normas, por lo menos: cinco en el español americano y tres en el europeo ${ }^{1}$. Y considerar cualquiera de ellas como superior

\footnotetext{
${ }^{1}$ Estas son, según Francisco Moreno (2014), las grandes normas del español. Dentro del continente americano, las zonas dialectales hispánicas con más personalidad son cinco. 1. un área mexicana y centroamericana (representada, por ejemplo, por los usos de la Ciudad de México y de otras ciudades y territorios significativos), 2. un área caribeña (representada, por ejemplo, por los usos de San Juan de Puerto Rico, La Habana, Santo Domingo o Caracas), 3. un área andina (representada, por ejemplo, por los usos de Bogotá, Quito, Lima o La Paz), 4. un área chilena (representada por los usos de Santiago) y 5. un área austral (representada por los usos de Buenos Aires, de Montevideo o de Asunción). Para el español de España se distinguen tres áreas generales: 1. una andaluza (que estaría representada por los usos de Sevilla, Málaga o Granada), 2. una canaria (representada por los usos de Las Palmas o Santa Cruz de Tenerife) y 3. una castellana (representada por los usos de ciudades como Madrid, Burgos o Cuenca). Estas ocho áreas cuentan con una amplia base común, que se manifiesta a través de los usos más cultos de la lengua, pero ofrecen su propia personalidad de un modo claro y reconocible por expertos y por no expertos.
} 
a las otras sería un error que solo se justificaría por ignorancia, cuando no por un intento de manipulación en el que ahora no vale la pena entrar.

\section{Hacia la adecuada formación lingüística del profesorado}

Es muy probable que la existencia de esa inseguridad ante la realidad lingüística que conduce a propuestas didácticas equivocadas se deba a que la formación de los docentes no es la óptima, ni en competencias didácticas ni, en general, de otros conocimientos. Al menos, en el ámbito de España habría mucho que mejorar (por lo que sabemos, la situación es similar en Hispanoamérica). Dejan bastante que desear los contenidos de Lengua Española en los estudios de magisterio y en los denominados másteres de educación, que, en teoría, forman futuros docentes de lengua con la doble finalidad: para L1 y para L2. Para ilustrar esta realidad y evitar herir sensibilidades, acudiré a la verosímil ficción literaria, donde el escritor, no comprometido con la realidad (en este caso léase con la Administración educativa, con la Inspección de educación, con los responsables de las instituciones), puede darnos una visión más acertada - por aquello del valor testimonial de la Literatura- de la que podrían ofrecernos estudios realizados sobre realidades concretas, que suelen falsearse con mucha frecuencia por razones, sobre todo, de tipo político.

Así, veamos, en primer lugar, cuál es la experiencia de un profesor de español que enseña a hablantes nativos, que ha tenido que ceñirse a los contenidos conceptuales, actitudinales y procedimentales de los «diseños curriculares» (en el caso de España) o planes de estudio prescritos y refrendados por ministerios u otras instituciones con competencias en estos asuntos. En segundo lugar veremos la experiencia de un profesor nativo que aspira a enseñar español como lengua extranjera en un país no hispano.

El primer caso lo protagoniza Manuel Vilas², y la anécdota está extraída de su novela Ordesa. Sí conviene aclarar que, aunque partamos de un hecho que en principio es fruto de la imaginación creadora del autor y no nos veamos obligados a atribuirle valor de testimonio real a lo narrado, nos consta que, efectivamente, el escritor ejerció la docencia en la asignatura de Lengua Española. En los siguientes párrafos se caricaturizan los áridos planteamientos de algunas cuestiones y la desconexión en ocasiones de los contenidos en relación con los intereses de los alumnos:

[...] Me pasaba el día explicando la tilde diacrítica. Todos los españoles que han ido a la escuela acaban distinguiendo el «tú» pronombre del «tu» adjetivo. No es el mismo «tu» en «tú piensas» que en «tu pensamiento». En el primer caso es pronombre y lleva tilde, en el segundo es determinante y no lleva tilde. $Y$ a eso me dedicaba. Me pasé veintitrés años contemplando a ese maldito «tu» 0 «tú». Y

\footnotetext{
2 Manuel Vilas (Barbastro, Huesca, 1962) es un reconocido poeta, novelista y colaborador de distintos diarios y suplementos culturales. Fue finalista del Premio Planeta con la novela Alegría, aunque ya había obtenido un notable reconocimiento por Ordesa (Alfaguara, 2018), que constituyó un verdadero fenómeno literario y que ha sido considerada como modelo del género autobiográfico; de ella hemos tomado estos fragmentos. Vilas es licenciado en Filología Hispánica y ejerció, durante más de veinte años, como profesor de enseñanza secundaria.
} 
por eso me pagaban. Estaba todo el día enseñando eso, que no es lo mismo «tú vienes» que «tu venida», era ridículo, sobre todo cuando no venía jodidamente nadie" (p. 49).

Reconoce el autor haber suspendido a los alumnos por no saber analizar sintácticamente frases, que, por cierto, es una de las actividades más repetidas en las clases de lengua:

Al principio, claro, cuando sales de la universidad repites como un loro las estupideces que allí te enseñaron, como las oraciones subordinadas de relativo, que eran mis preferidas: había en ellas una flexibilidad, había árboles y flores y cielos en aquellas subordinadas. Me quedaba mirando con mis alumnos las oraciones subordinadas de relativo. Recuerdo esta:

He leído el libro que me prestaste ayer.

Pero casi prefería no analizarlas. Nos quedábamos mirando las frases en la pizarra. ¿Qué libro sería? ¿Quién sería la persona destinataria del préstamo? ¿Valió la pena leer ese libro? ¿No hubiera sido mejor que te prestaran cualquier otra cosa, en vez de un libro?

Nos moríamos de risa con el objeto directo en frases como esta:

Juan quemó el coche.

¿Quién demonios era Juan? ¿Era un buen coche? ¿Por qué quemar un coche? El colmo era cuando pasabas la oración a pasiva, porque esa era la forma de comprobar que «coche» era el maldito complemento directo:

El coche fue quemado por Juan.

Si la frase tenía sentido, el jodido «coche» era el complemento directo. Nos quedábamos pensando, mis alumnos y yo, de quién sería el coche que Juan había quemado. Yo pensaba en mi coche, en que si Juan quemaba mi coche, yo mataba a Juan.

El complemento directo representaba al proletariado de la sintaxis, tenía que cargar con todo, tenía que cargar con la acción del verbo.

Muchas veces yo he sido un complemento directo. Siempre cargando con el verbo, con la tiranía del verbo, que es la violencia de la Historia.

Practicaba una explicación marxista de la sintaxis. Un marxismo cómico, pero al menos nos moríamos de risa. Estoy siendo injusto: el único aliado leal de la redención social de los españoles desfavorecidos es el profesorado. Tuve inmejorables amigos allí. Vi profesores excelentes, pero el sistema educativo agoniza; eso es, en realidad, lo que quería decir, que el sistema educativo ya no funciona porque se ha quedado varado en el tiempo. (pp. 111-114)

El segundo ejemplo «literario», que no ficticio, según parece, que voy a ofrecer pertenece al escritor colombiano, también profesor en alguna etapa de su vida, Héctor Abad Faciolince $^{3}$. Su experiencia es la del profesor hablante de una modalidad

\footnotetext{
3 Héctor Abad Faciolince (Medellín, 1 de octubre de 1958) es un escritor y periodista más conocido por sus libros Angosta, que obtuvo en abril de 2005 en China el premio a la mejor novela extranjera, y El olvido que seremos, sobre la vida y asesinato de su padre. De reciente aparición es Lo que fue presente (Diarios 1985-2006), Madrid, Alfaguara, 2020. Estudió lenguas y literaturas modernas en la Universidad de Turín. Los textos que se exponen aquí están tomados de su libro Traiciones de la memoria (Un camino equivocado), Madrid, Alfaguara, 1973.
} 
meridional del español que los alumnos -italianos- no reconocen como modalidad de prestigio.

El protagonista, necesitado de trabajo en Italia, decide impartir clases de español, pero es rechazado por su acento colombiano, hasta que, gracias a su experiencia con un profesor de español de la modalidad septentrional que había tenido, decide cambiar de dialecto, y hasta de personalidad:

Yo no podía dar clases de español. Mejor dicho, sí podía, podía perfectamente, pero los italianos no confiaban en mí. Yo no era español. Yo era colombiano, y los suramericanos hablamos, según ellos, un castellano espurio, feo, inculto, subdesarrollado. Yo ponía todas las semanas avisos en La Stampa: «Lezioni private di spagnolo. Insegnante di madrelingua». Y el teléfono. Llamaban algunas personas, estudiantes, amas de casa desocupadas o hartas de su oficio, comerciantes de corbatas... Todo iba bien, el precio les parecía correcto, el horario adecuado, hasta que preguntaban: «Ma lei, di dov'è?». Sono colombiano. «Columbiano? Davvero columbiano?». Preguntaban aterrorizados, y hasta ahí llegaban las clases; en pocos segundos ya habían sacado una disculpa y cancelado la primera lección. Algunos llegaban a la primera clase sin hacer la pregunta fatídica, pero en cuanto se enteraban de mi origen suspendían las clases de español. «No, mi spiace, ma io devo imparare uno spagnolo vero, autentico». Buscaban en mi español el certificado DOC, como en los vinos.

[...]. Resolví dejar de ser colombiano y me convertí en español. Incluso, por seguridad, me inventé una biografía. [...] Tenía que solucionar también el problema del acento, pero no era tan difícil gracias a que en el colegio donde yo había estudiado había sido rector un psicólogo español, don Miguel Briñón, y mi pasatiempo favorito en los primeros años de bachillerato (pasatiempo que una vez casi me cuesta la expulsión) había sido imitar su voz y su manera de hablar. Así que me declaré nacido en Palencia y empecé a hablar como Miguel Briñón.

Vosotros bien sabéis que en las Indias occidentales no solemos usar la segunda persona del plural. Sabéis también que es necesario redondear un poco la pronunciación de la ese y, lo que es más difícil, que se requiere escupir un poco con los dientes al pronunciar las zetas y la ces. Pues vale, si eso es lo que queréis, os daré todas las zetas que queráis, y no diré nunca más muchacho sino chaval, y no manejaré carros sino que conduciré coches, y en vez de medias me pondré calcetines, y no habrá malparidos entre mis conocidos sino solo jilipollas, y la vista del escote de la mujer del prójimo ya no me pondrá arrecho sino cachondo. Era difícil, pero no imposible. Y el efecto fue inmediato, mis alumnos se multiplicaron como por arte de magia. Bastaba dejar de ser colombiano para poder empezar a ganar algo más de dinero en Italia, con un tipo de astucia (el fingimiento) que es una argucia de raíz latina, es decir, italiana, cuyos latidos llegaron hasta Colombia por el mismo camino de nuestra lengua. (pp. 223-226)

[...] En Europa fui informado de que yo no sabía hablar español. [...]. Me sembraron la duda de que yo hablaba mi propia lengua sin propiedad, como si fuera un extranjero. Es como vivir en un cuerpo prestado, hablar en una lengua que no es la propia, y hablar la lengua propia como si fuera ajena, era como salirse del propio cuerpo. Uno puede dominar los idiomas extranjeros; lo que pasa con la lengua materna es que ella, la lengua, es la que lo domina a uno. Uno puede moverse en esa lengua como en una feliz inconsciencia. Es horrible tener conciencia de la propia manera en que se habla. Como esas personas que llevan 
a la televisión o se encuentran con alguien que consideran muy culto y empiezan a cambiar su manera correcta y espontánea de hablar por una fingida e irremediablemente incorrecta. (pp. 230-231).

Por fortuna, hoy, estos ejemplos de Vilas y Abad Faciolince empiezan a tener ya casi un exclusivo interés literario; a lo sumo, confío en que puedan poseer el valor de una llamada de atención para quienes supeditados a directrices obsoletas o actitudes indeseadas de discriminación lingüística tengan la valentía de superarlas con el bien hacer, con el trabajo, con el rigor.

La propia experiencia de Héctor Abad había sido objeto de comentario en el sentido totalmente opuesto, pues, hoy, para algunos aspirantes a aprender español parece que no es la norma castellana o septentrional la más prestigiosa; y, así, por ejemplo, valga esta reseña a Traiciones de la memoria, en la que su autor, J. Salavert (10/24/2011), considera poco creíble o ridícula la anécdota de que por su acento colombiano Héctor Abad no hubiera conseguido trabajo como profesor de español:

De ser totalmente cierta [...], solamente me cabe decir que para su desgracia, Abad aterrizó en el esperpéntico inframundo de la enseñanza del castellano. Le doy el ejemplo de una de las más prestigiosas universidades australianas: ¿Y si le dijera yo a Abad Faciolince que por estos pagos es quizás [...] el acento de las zetas y las ces, que él tuvo que 'adoptar' para poder captar alumnos de clases particulares en Turín, contra el que se ejerce la discriminación que él denuncia? Claro que, al menos, a algunos nos queda el consuelo de que el haber aprendido el idioma con ese acento te asegura saber sin vacilación alguna cómo se escriben palabras como "piscina" o "conciso", por poner solamente un par de ejemplos.

Deficiencias didácticas, erradas actitudes, cierta inseguridad es lo que pueden explicar las anteriores anécdotas, por considerarlas como tales.

Hace unos años, traté de comprobar mis sospechas y realicé unas indagaciones sobre este asunto de la formación de los docentes; concluía que las competencias que se poseían eran insuficientes: las calificaba de lábiles, pues tan poca consistencia mostraban. Algunas de las debilidades en la formación de los docentes que se observaban en los distintos niveles lingüísticos (Hernández, 2016) afectaban a las competencias fonológica, ortográfica, gramatical y lexicosemántica; incluso un pobre dominio en el uso de recursos imprescindibles para una correcta didáctica de la enseñanza de la lengua, como son los diccionarios:

Si no se saben leer (consultar) los diccionarios, podría ocurrir que se exigiese, como se ha hecho, que se supriman de la lengua (y de los propios diccionarios) palabras como judío, con el sentido de 'persona avariciosa', o gitano en el sentido de 'que estafa, que actúa con engaño, trapacero', pues se ignora que un buen diccionario, que debe registrar, por supuesto, la voz y la acepción, las marcaría oportunamente como despect., abreviatura que significa 'que expresa una idea de menosprecio'. Incluso, la falta de competencia lo llevaría a afirmar que podemos utilizar la voz gilipollas con el sentido de 'estúpido o necio', por el hecho de estar en el diccionario, por no saber 
interpretar que la palabra en cuestión está calificada como malsonante (malson., abreviatura que significa 'que ofende al pudor o al buen gusto'). Quien procediese así demostraría una competencia pragmática lábil.

Es este un buen lugar para señalar que una clara y exhaustiva información pragmática es fundamental en un diccionario que vaya a destinarse a usuarios extranjeros.

Terminaba diciendo que no hubiera expresado tantas labilidades si no fuera porque las conclusiones a las que habíamos llegado eran el resultado de observaciones reales, unas veces manifestadas explícitamente por algunos docentes (es ilustrativa la confesión de H. Abad Faciolince [2015] $]^{4}$ ), y otras descubiertas a través de muchos escritos, incluso en escritores de prestigio. Y porque he comprobado, además, que, so pretexto de progresía, se rehúye e infravalora todo lo que sugiera «norma», tal vez para ocultar estas lábiles competencias. Se ignora, quizá, que las reglas que regulan el funcionamiento de una lengua nos las hemos dado entre todos, los que nos han precedido en su uso (los grandes autores de nuestra tradición literaria) y los que somos sus usuarios hoy; al menos los que, respetuosos con este preciado patrimonio cultural que es la lengua, seguimos empeñados en tratar de mantenerla unida -a pesar de ser conscientes de su mutable vitalidad-y con la capacidad para cumplir con sus múltiples funciones: prácticas, intelectuales y literarias. Resultaba, además, ilustrativa una de las conclusiones de un trabajo que trataba precisamente de la evaluación de competencias (Hernández Muñoz, 2015: 94-95), en este caso de la competencia léxica. Dice así:

Para terminar, añadimos una conclusión de carácter pedagógico: la competencia léxica del hablante adulto se ve favorecida, al menos en los procesos de actualización, por las habilidades metalingüísticas [capacidad para reflexionar sobre la lengua y sus reglas] del sujeto y en concreto, por el dominio de los procesos derivativos de la morfología léxica. De ahí la necesidad de insistir tanto en la enseñanza obligatoria como en la educación adulta, formal y no formal, en el conocimiento metalingüístico como estrategia para el acceso al léxico ${ }^{5}$. Un entrenamiento específico puede influir en las tareas de fluidez semántica, pero también en la producción de textos escritos, la realización de pruebas de evaluación y, en resumen, en un mayor aprovechamiento de las habilidades lingüísticas y comunicativas del individuo.

Y esta conclusión puede extrapolarse al resto de las competencias lingüísticas y comunicativas, sin lugar a dudas.

\footnotetext{
4 «Cuando fui maestro de lengua española, todavía lo recuerdo con dolor en el alma, una colega me corrigió dos errores que cometí en el tablero: había escrito jesuita con tilde (jesuita) y también le había puesto tilde al pronombre ti (ti). Jamás olvidaré esas correcciones [...]».

${ }^{5}$ La cursiva es nuestra.
} 


\section{Algunas propuestas para la formación de los docentes}

Persiste la creencia de que no se precisa un conocimiento tan profundo de la lengua para enseñarla en determinados niveles de la enseñanza con determinado tipo de alumnos, pues este dominio solo se les exige a los expertos. Ignacio Bosque (2018: 1136) mantiene que la enseñanza de la gramática ha de ocupar un lugar importante. No bastan para enseñar Lengua Española - explica- las informaciones de usuario, sino que se precisan conocimientos de experto, pues los hablantes no somos simples usuarios de un instrumento que es externo a nosotros sino que, por el contrario, lo tenemos interiorizado y «constituye una parte esencial de nuestra naturaleza, y nadie es usuario de su propia naturaleza: los hablantes no somos usuarios de nosotros mismos». Advierte Bosque de ciertos riesgos que suelen darse en estas situaciones de enseñanza, como es el que denomina problema de la complicidad con el destinatario, pues se asume implícitamente que se comparten algunos contenidos: «no voy a entrar a explicar lo que todos ya sabemos», o «no hace falta que te diga lo que tú sabes lo que yo sé que tú sabes». «Esta complicidad -dice Bosque- puede dificultar la comprensión científica de cualquier sistema que posea cierto grado de complejidad». Es preciso «prescindir absolutamente de la complicidad con el interlocutor y formular con absoluta explicitud cualquier variable que pueda ser pertinente, empezando por las que nunca se formulan porque parecen evidentes o de sentido común».

Existe, por otra parte, la obsesión terminológica, que se da cuando «Prestamos [...] más atención a cómo se llaman las cosas que a lo que son las cosas; nos importa mucho más saber identificarlas que distinguir sus propiedades y sus límites» (2018).

\section{El problema de la diversidad de normas}

No es poca, pues, la formación que debería poseer un profesor de lengua, exigencia que se multiplica cuando, además del conocimiento profundo del sistema lingüístico en general, debe sumar aquel que se deriva de una incontrovertible realidad: la diversidad de normas.

Obviar la variación lingüística (diversidad de lenguas y de dialectos) sería negar la realidad. Claro que resulta muy cómodo desde una perspectiva no hispana considerar que solo hay una norma estándar del español, que esa norma cuenta con el respaldo de una institución cuyo prestigio y autoridad nadie pone en duda, la Real Academia Española, y esto por no decir que esta «verdadera» modalidad puede aprenderse o adquirirse en determinados centros y universidades. Pero nada más lejos de la realidad: una lengua es una integración de dialectos con el mismo nivel jerárquico, y esta pluralidad de modalidades no constituye una condena, sino un enorme patrimonio que habrá que proteger, promocionar y conocer ${ }^{6}$. Rosa Montero (2013) dice, con palabras que comparto, que

${ }^{6}$ La propia Constitución Española, que en su artículo 3.1. prescribe que «El castellano es la lengua española oficial del Estado» y que «todos los españoles tienen el deber de conocerla y el derecho a usarla», reconoce en el 3.2. que «La riqueza de las distintas modalidades lingüísticas de España es un patrimonio cultural que será objeto de especial respeto y protección». 
La mayor riqueza del español no reside en su enorme implantación, sino en su diversidad, en sus muchas versiones y matices. En este mundo crispado, sectario y excluyente, emociona poder celebrar una lengua común llena de diferencias que no solo no desunen, sino que potencian.

Y no es la variación dialectal y su consideración como riqueza cultural una peculiaridad exclusiva del español. Kory Stamper (2018: 79), lexicógrafa y editora de la familia de diccionarios Merriam-Webster, ha escrito, recientemente, una reflexión semejante para la lengua inglesa:

[...] el inglés estándar es un dialecto basado en un ideal escrito que aprendemos con la educación formal. [...]. El hecho de que debemos aprender inglés estándar demuestra que no es nuestro dialecto nativo. Pero no pasa nada: en la práctica, los hablantes nativos de inglés hablan muchos dialectos de inglés y en general saltan de uno a otro según las circunstancias. ¡Los dialectos son geniales!

La diversidad de lenguas y la pluralidad de dialectos es una realidad que tenemos que afrontar; asimismo, debemos ser conscientes de las limitaciones que imponen, pues no podemos conocerlos todos; no solo no podemos conocer todas las lenguas -esto parece obvio-, sino que difícilmente podemos dominar todas las modalidades de una misma lengua; en nuestro caso, las distintas modalidades del español. Por esta razón, se tienden a buscar criterios que prioricen el aprendizaje de una lengua entre los miles de idiomas existentes (su reconocimiento como lengua de prestigio o su carácter de lingua franca, por ejemplo) o la elección de una modalidad dialectal que se considere abarcadora de todas las demás.

En dos pueden resumirse las propuestas que suelen hacerse en relación con este problema, aparentemente insoluble, y todas ellas están orientadas a eliminar de forma artificiosa la complejidad de la realidad de la variación lingüística. Una de ellas es la de proponer la enseñanza de un hipotético español neutro, un español internacional que elimine lo diferente para reducirlo a lo general, más fácil de acaparar y de afrontar didácticamente, pero menos real y expresivo. La otra posibilidad sería la ideal, si pudiera aceptarse que existe un español estándar; pero no vamos a entrar una vez más en asunto tan complejo y debatido como es la realidad del carácter pluricéntrico del español, esto es, reconocer la existencia de varios modelos que no son otra cosa que los diferentes estándares ${ }^{7}$.

Una forma factible y recomendable de proceder consistiría en adoptar criterios objetivamente indiscutibles para hacer viable la variación compatibilizándola con el

\footnotetext{
${ }^{7}$ La lengua estándar es la utilizada como modelo por estar normalizada, de acuerdo con las normas prescritas, como correcta. Esta es la lengua que usan los profesionales de los medios de comunicación, los docentes y otros profesionales, y dado que se reconocen distintas modalidades, cabe hablar de un español estándar de ámbito general (la norma culta escrita) y un estándar andaluz, canario o mexicano.
} 
principio de igualdad de todas las variedades. Una estrategia viable y sensata es la propuesta por Francisco Moreno Fernández (2007) que consiste en primar «en primer lugar, lo correcto sobre lo incorrecto; que, allí donde no llega la normativa, prime lo culto sobre lo inculto; y que, allá donde lo culto ofrezca soluciones diferentes, prime lo general sobre lo particular. Lo correcto; lo culto; lo general.

Por supuesto, para poder seguir adecuadamente estas propuestas es preciso que el enseñante posea conocimientos de las distintas disciplinas lingüísticas y dominio de las estructuras de la lengua que enseña para que, pertrechado en sus conocimientos, pueda seleccionar y construir sus propios métodos de enseñanza y decidir el estándar que en cada caso conviene enseñar. Es preciso, por ejemplo, que posea un buen dominio de la fonética y la fonología; así, a partir de la enorme variación que se da en este plano de la lengua pueda llegar a las conclusiones que le permitan determinar qué es lo considerado correcto, lo culto y lo general.

\section{Cómo afrontar la variación fónica}

La complejidad de las variantes fónicas del español, desde el norte peninsular hasta el sur del continente americano, pueden resumirse en unas pocas normas, según lo ha expuesto Raúl Ávila en sus trabajos (2003: 11-25). Parte el investigador mexicano de la posición implosiva o explosiva de los fonemas consonánticos. Atendiendo a la posición explosiva, y teniendo en cuenta la tendencia general del idioma hacia el yeísmo, nos encontramos con dos sistemas fonológicos: uno, el más extendido, es el seseante, el que neutraliza la oposición entre /s/y / $\theta /$; el otro, con una población minoritaria, es el que distingue los dos fonemas anteriores.

1) Un sistema seseante con dos normas

Norma $\alpha$ : seseo y mantenimiento de $-s$ implosiva

Norma $\beta$ : seseo y aspiración [h] de $-s$ implosiva

2) Un sistema distinguidor

Norma $\gamma$ : distinción /s/ : / $\theta$ / y mantenimiento de $-s$ implosiva

Si se atiende a la posición implosiva nos encontramos con que el primer sistema tiene dos normas de uso general, que este autor denomina norma $\alpha$ y norma $\beta$; y en el segundo sistema sólo una norma, la $\gamma$. «La norma $\alpha$ mantiene el fonema /s/ en posición implosiva; la $\beta$, que se escucha, por ejemplo, en Caracas, presenta aspiraciones de /s/, 
aunque menos frecuentes que en la lengua hablada culta. La norma $\gamma$ se distingue de las otras [...] por diferenciar /s/ de / $\theta$ / y porque el fonema /s/ tiene una pronunciación más grave que la que se escucha en las otras normas».

Aunque la situación no es tan sencilla y cada una de estas normas puede, a su vez, presentar algunas variantes ${ }^{8}$, este planteamiento tiene la ventaja de ofrecer una descripción más ajustada a la realidad que si se hiciera como una acumulación de rasgos, que es como suelen caracterizarse las distintas normas.

Si se considera la difusión a través de los medios de comunicación audiovisuales de las normas antes descritas como indicador de aceptabilidad, la más preferida por las audiencias es la que denomina $\alpha 1$, caracterizada por el seseo, mantenimiento de $-\mathrm{s}$ implosiva y pronunciación del fonema /x/ como fricativo. Y, si se toman en cuenta los aspectos demográficos, no cabe duda de que «las dos primeras normas son las mayoritarias, y por eso las favorecen las empresas de televisión. La tercera, en cambio, sólo se escucha en los canales españoles que difunden a nivel internacional» ${ }^{9}$.

A muchos sorprendería que desde esta perspectiva objetiva y universal sea una norma seseante la que más se ajusta a los criterios antes mencionados de lo correcto, lo culto y lo general. La tradición didáctica suele prestigiar la norma minoritaria, la $\gamma$, que es la distinguidora, pues el seseo se ha considerado como un rasgo «dialectal», no olvidemos que desde la edición de 1884 del DRAE hasta la de 1970, sesear se definía como «Pronunciar la ce como ese por vicio o por defecto orgánico», y se mantiene con cierta vigencia la perspectiva castellanizante, así, por ejemplo, A. Salvador Rosa (2015: 182-183) afirma lo siguiente:

En la escuela, que es ámbito de transmisión cultural, no cabe otra pronunciación que la modélica, porque sin duda existe un modelo de corrección. Los modelos se pueden construir según la conveniencia, es cierto, pero no cuando ya hay uno avalado por la tradición y salvaguardado por el prestigio. El español hablado no carece de ese modelo, desde luego. Y por si no bastara, ahí está nuestra escritura, la más fonológica de cuantas puedan citarse entre las de las lenguas que han dispuesto siempre de sistema alfabético. ¡Qué sencillo en estas circunstancias, mantener el ideal de pronunciación! Pues la escritura, aunque imperfectamente, es ya una forma de transcripción de esa pronunciación

\footnotetext{
8 "Las tres normas [...] tienen algunas variantes dentro de los medios de comunicación. A continuación describiré las más características, con base en investigaciones preliminares sobre la pronunciación que se escucha más frecuentemente en la radio y la televisión. La norma $\alpha$ seseante tiene dos variantes. En $\alpha 1$ el fonema /x/ es casi siempre fricativo, como en la pronunciación de locutores o actores de la ciudad de México [...]. En la variante $\alpha 2$, menos frecuente, la pronunciación de /x/ es un poco abierta $[x]$, como la de los hablantes cultos de la ciudad de Bogotá [...].

La norma $\beta$, seseante y con aspiración de /s/ en posición implosiva, presenta asimismo otras variantes. La primera $\beta 1$, se caracteriza por la presencia de [ $\eta$ ] velar final de palabra, la pronunciación abierta [h] del fonema /x/,y fricativa un poco abierta [y] del fonema /y/, como se escucha en la televisión de Caracas [...]. En la segunda, $\beta 2$, no ocurre la $n$ velar final, el fonema $/ \mathrm{x} /$ se pronuncia fricativo, hay menos aspiraciones de [s] y se escucha tenso y rehilado el fonema /y/, como en la mayoría de los programas de Buenos Aires [...]. La tercera, $\beta 21$, es una variante de la anterior en la cual el fonema $/ y /$ se pronuncia rehilado ensordecido, como en algunos locutores de la misma ciudad [...].

La norma $\gamma$ se caracteriza suficientemente por ser seseante, pronunciar [s] apical y $[\mathrm{x}]$ un poco vibrante, como se escucha entre madrileños cultos [...]. Cabe añadir que también se escucha la [n] velar final de palabra en algunos locutores. Sin embargo, su frecuencia es menor que la que se escucha en la norma $\beta 1$, aunque parece ser mayor que la que se presenta en las normas $\alpha 1$ y $\alpha 2 "$ (Ibíd.).
}

9 Ibíd. 
que, en un momento determinado de la vida del idioma se ha querido plasmar en una representación gráfica. [...] En los términos más simples, si se reconoce la necesidad de una norma referencial para la correcta comunicación, la única que cumple los requisitos para ser generalmente aceptada en el mundo hispánico es la norma culta que, en determinados aspectos, coincide con la tendencia castellanista. Ninguna otra norma podría alcanzar el necesario carácter modélico, sino por el sistema de la cruda imposición. La disyuntiva es, pues, esta: si queremos una norma ejemplar, la que hay; si no queremos la que hay, ninguna. (p. 183).

Quien así opina desconoce que «los modelos» los construye la propia comunidad hablante, y no una institución o autoridad lingüística o política; que alegar un respeto firme a la «tradición» es negar el principio de mutabilidad lingüística (las lenguas cambian, también las normas).

Hay quien sorprendentemente en recomendaciones para el uso mediático otorga con benevolencia y generosidad validez al seseo SOLO en el ámbito del español americano, no así en «emisiones destinadas a toda España» (Medina Guerra, 2002: 201):

[...] parece obvio, dada su estimación social, que no supone ningún problema la pronunciación seseante en las emisoras de radio y televisión de los países hispanoamericanos; sin embargo, al menos de momento, no lo creemos recomendable en emisiones destinadas a toda España, donde siguen siendo muchos los hablantes distinguidores y el seseo sólo se considera correcto en Canarias y en algunas zonas del sur peninsular.

\section{Sobre la variación gramatical}

La variación gramatical suele presentarse simplificada en dos grandes normas caracterizadas por la presencia / ausencia del pronombre vosotros. Existencia de la distinción entre los pronombres vosotros (plural de tú) / ustedes (plural de usted), en el español septentrional o castellano, y ausencia de vosotros en la modalidad meridional o atlántica, con un único pronombre ustedes que semánticamente incluye el plural del tú y del usted: no posee, pues, en esta modalidad ustedes ningún valor de cortesía. Ausencia que implica, a su vez, la no utilización del pronombre átono de segunda persona os, ni la desinencia verbal correspondiente ( $Y a$ os vais / ya se van). Igualmente, desaparece, salvo excepciones, el posesivo vuestro.

Es verdad que la situación presenta una mayor complejidad, y bueno será para los profesores de español conocer los sistemas pronominales de mayor extensión, para que siguiendo el criterio anterior (lo correcto, lo culto y lo general) puedan llegar a conclusiones adecuadas a cada situación de aprendizaje.

A continuación se ofrece un panorama de la situación de los sistemas pronominales a partir del estudio de M. ${ }^{\text {a }}$ Beatriz Fontanella de Weinberg (1999: 1399-1425). Estos son los sistemas pronominales más extendidos: 
Sistema pronominal I

\begin{tabular}{|lll|}
\hline & SINGULAR & PLURAL \\
\hline Confianza & tú & vosotros/as \\
Formalidad & usted & ustedes \\
\hline
\end{tabular}

Extensión del sistema I: se extiende por la España peninsular, salvo en las zonas de Andalucía en las que se emplea el sistema II. Es el único de los sistemas del mundo hispánico en el que actúa la oposición confianza / formalidad para plural, ya que en los restantes está neutralizada.

Comentario: En la región en que se da este sistema es muy frecuente el leísmo, pues le y les se emplean como complemento directo.

Sistema pronominal II

\begin{tabular}{|lll|}
\hline & SINGULAR & PLURAL \\
\hline Confianza & tú & \\
& & ustedes \\
Formalidad & usted & \\
\hline
\end{tabular}

Extensión: El ámbito de este sistema es muy extenso: territorios de la Península Ibérica (Andalucía occidental, y partes de Córdoba, Jaén y Granada), Canarias ${ }^{10}$ y vastas zonas de América (Casi todo el territorio mexicano, y peruano, las Antillas, gran parte de Colombia y Venezuela).

Comentarios: En las zonas donde se da este sistema no se suele producir el leísmo (ni laísmo ni loísmo). Además, al desaparecer el posesivo vuestro, las únicas formas son su/s, suy-o/a/os/as, lo que provoca una amplia homonimia (por ejemplo, ¿Dónde están sus carpetas? = 'sus carpetas de usted', 'sus carpetas de ustedes'. Para evitar la ambigüedad se recurre a la forma analítica de ustedes: ¿Dónde están las carpetas de ustedes?

A veces, en la lengua escrita se usa el posesivo vuestro/a/os/as, como en el sistema I.

Puede observarse, además, un uso de vosotros (-as) con cierto valor de solemnidad, y no como plural de tú.

${ }^{10}$ En zonas rurales de La Gomera, El Hierro y La Palma se mantiene un uso arcaizante de vosotros y os/vos: así, por ejemplo, en lugar de vosotros os vais se escucha [bosotrosh buh bais]. 
Sistema pronominal III

IIIa

\begin{tabular}{|lll|}
\hline & SINGULAR & PLURAL \\
\hline Confianza & vos - tú & \\
& & ustedes \\
Formalidad & usted & \\
\hline
\end{tabular}

Extensión: Este sistema se da en Chile, gran parte de Bolivia, sur del Perú, parte de Ecuador, gran parte de Colombia, el oeste venezolano, las regiones limítrofes de Panamá y Costa Rica y el estado mexicano de Chiapas

Comentario: La coexistencia del voseo y el tuteo no tiene una delimitación funcional, más allá de la preferencia de tú en los hablantes más cultos y en los estilos más cuidados

$I I I b$

\begin{tabular}{|lll|}
\hline & SINGULAR & PLURAL \\
\hline Intimidad & vos & \\
Confianza & tú & \\
& & ustedes \\
Formalidad & usted & \\
\hline
\end{tabular}

Extensión: Este sistema se da sobre todo en Uruguay

Comentario: Existen aquí tres niveles de formalidad: vos, íntimo; tú de confianza y usted en el uso formal. Tanto vos como tú van regularmente acompañados por formas verbales voseantes monoptongadas: vos cantás, temés, partís; tú cantás, tenés, partís.

Sistema pronominal IV

\begin{tabular}{|lll|}
\hline & SINGULAR & PLURAL \\
\hline Confianza & vos & \\
& & ustedes \\
Formalidad & usted & \\
\hline
\end{tabular}

Extensión: Es el sistema empleado de forma generalizada en territorio argentino, y también, según datos bibliográficos, en Costa Rica, Nicaragua, Guatemala y Paraguay. En El Salvador y Honduras se emplea ampliamente, aunque puede alternar con el uso de tuteo 
Comentario: Es un sistema con dos únicas formas para el singular que se oponen por formalidad: vos y usted. La forma vos como forma de confianza está totalmente generalizada y no existe ningún tipo de alternancia o contraste con tú, que resulta una forma ajena a la comunidad.

Como se deduce de lo expuesto anteriormente, el sistema pronominal menos extendido es el sistema I, aunque por tradición goza de mucho prestigio.

El sistema II es con diferencia el más general; también lo acompaña el prestigio que lo respalda su uso en gran parte del español americano, Canarias y parte del sur peninsular, con la ventaja, además, que en las zonas en las que se da no suelen producirse casos de leísmo, laísmo y loísmo.

Los sistemas II al IV presentan como rasgo común contar con un único pronombre ustedes que se usa tanto para tratamiento respetuoso como para el uso familiar; es general en el español de Canarias y en el de América. «Esporádicamente -dice L. Gómez Torrego (2011: 326) - se encuentra en Canarias y América el uso de vosotros (-as), pero usado como forma solemne, y no como plural de tú»

\section{Algunas propuestas para el nivel léxico}

Como es bien sabido, el léxico es el sistema más abierto de la lengua (frente al carácter cerrado y limitado de los planos fonológico y gramatical); por ello solo cabe hacer una serie de recomendaciones generales:

1. Que hay léxico de carácter general o común a todas las variedades de la lengua y un conjunto menor de léxico particular de cada modalidad, al que suele denominarse léxico diferencial. Conviene reflexionar sobre tal denominación, puesto que hay un buen número de unidades particulares de una modalidad que no se diferencian de otras generales, es decir, no contrastan con ninguna otra de la lengua general: denominaciones de especies autóctonas, por ejemplo, comidas, costumbres; así, voces como tajinaste (una planta) y gofio (un alimento) podríamos considerarlas como voces generales cuyo ámbito de uso es sobre todo el del archipiélago canario. Algo similar podríamos plantear con palabras como joropo y hallaca: aun siendo originarios de Venezuela el baile y el alimento, ¿habría que considerarlos como venezolanismos?.

2. Que hay que ayudarse de los diccionarios, de los buenos diccionarios, en los que encontramos la información gramatical, semántica y pragmática para realizar con éxito las tareas de descodificación y codificación. Téngase en cuenta, además, que no solo hay repertorios diferenciales para las distintas modalidades del español, también los hay integrales, que merece la pena consultar si enseñamos español en determinadas áreas. (Vid. Hernández, 2013).

\section{Conclusiones generales}

De lo expuesto anteriormente pueden extraerse las siguientes conclusiones generales: 
a. No existe una única norma del español -el español es una lengua pluricéntricaque por razones lingüísticas merezca el reconocimiento como referencia indiscutible para su enseñanza, ya sea como lengua materna o como lengua extranjera.

b. Dentro de las dos grandes normas del español (la septentrional o castellana y la meridional o atlántica) se insertan, al menos, ocho modalidades (tres en el español de España y cinco en el americano) perfectamente identificadas por rasgos característicos en los niveles fónico, gramatical y léxico

c. Para una correcta enseñanza del español es preciso que el profesorado, además de las competencias pedagógicas exigidas, posea un amplio conocimiento de la variación dialectal y el total convencimiento de que procederá correctamente enseñando la norma que mejor conozca, procurando siempre relacionarla con las otras, con el fin de enriquecer la competencia comunicativa y cultural de sus alumnos.

Estas conclusiones pueden ilustrarse con las propias observaciones de Francisco Moreno Fernández (2014). Así, por ejemplo, atribuye al desconocimiento de las normas cultas del español, el caso de un responsable de un Instituto Cervantes que había pedido a una profesora en prácticas de origen canario que «abandonara el tratamiento ustedes en el plural y lo sustituyera por vosotros para dirigirse a los estudiantes. El argumento que daba el responsable académico era que el tratamiento de vosotros favorecía la espontaneidad y la cercanía hacia los aprendices; como si los andaluces, canarios, caribeños o argentinos estuvieran incapacitados para expresar tal cercanía por medio del único pronombre del que disponen para la segunda persona del plural: ustedes».

El otro caso que expone Moreno Fernández, y que también interpreta como desconocimiento de las normas cultas del español, es el de «una profesora estadounidense que interpuso una denuncia contra la Universidad de Pittsburgh, donde daba clases de español, al considerar que su contrato no fue prolongado por tener acento peninsular [...], pues su directora, una profesora de origen boliviano, no aceptaba que el profesorado tuviera acento europeo. Semejante conducta evidencia -afirma Moreno Fernández- una falta de respeto hacia otra norma culta del español, tan válida como la boliviana».

Ni el español de Castilla es el estándar, ni el español de España es la lengua del Imperio. Y sobra cualquier tipo de comentario.

\section{Referencias bibliográficas}

ABAD FACIOLINCE, H. (2015). Maestros de dudosa ortografía. El Espectador, 5 de septiembre.

ABAD FACIOLINCE, H. (1973). Traiciones de la memoria (Un camino equivocado). Madrid. Alfaguara.

ÁVILA, R. (2003). La lengua española y sus variantes en los medios de comunicación masiva. En: G. WOTJAK [ed.], Pautas y pistas en el análisis del léxico hispano(americano). (pp. 11-25). Madrid. Iberoamericana, 2003. 
BOSQUE, I. (2018). Qué debemos cambiar en la enseñanza de la gramática. RoGrOC/Revista de Gramática Orientada a las Competencias, 11-36 (digital).

FONTANELLA DE WEINBERG, M. a B. (1999). Sistemas pronominales de tratamiento usados en el mundo hispánico. En: I. BOSQUE Y V. DEMONTE (dirs.), Gramática descriptiva de la lengua española (pp. 1399-1425). Madrid. RAE/Espasa, vol I.

GÓMEZ TORREGO L. (2011, 4. ${ }^{\text {a }}$ ed.). Hablar y escribir correctamente. vol II. Madrid. Arco Libros.

HERNÁNDEZ H. (2013). Extensión del corpus y capacidad pedagógica de los diccionarios: los repertorios didácticos integrales. LEA (Lingüística Española Actual, vol, 35, 1, 109-126.

HERNÁNDEZ, H. (2016). Las competencias lábiles: reflexiones en torno a la formación lingüística del profesorado de español. En: O. CRUZ MOYA [ed.], La formación y competencia del profesorado de ELE (pp. 451-460). Granada. ASELE.

HERNÁNDEZ MUÑOZ, N. (2015). La evaluación de la competencia léxica adulta: una aproximación a través de la disponibilidad léxica y la especialización académica en preuniversitarios. Revista de Filología, 33, 79-99.

INSTITUTO CERVANTES (2010-2020). Plan Curricular. Niveles de referencia para el español: https://cvc.cervantes.es/ensenanza/biblioteca ele/plan curricular/

MEDINA GUERRA, A. M. $\underline{\text { a }}$ (2002). Ortología. En: M. $\underline{a}$ V. ROMERO [coord.], Lengua española y comunicación (pp. 180-211). Barcelona. Ariel.

MONTERO, R. (2013). Palomear. El País, 22 de octubre.

MORENO FERNÁNDEZ, F. (2007, 2.ํㅜ). Qué español enseñar. Madrid. Arco/Libros.

MORENO FERNÁNDEZ, F. (2014). Español de España - Español de América: Mitos y realidades de su enseñanza. FIAPE. $V$ Congreso internacional: ¿Qué español enseñar y cómo? Variedades del español y su enseñanza. Cuenca, 25-28 de junio de 2014.

SALVADOR R. (2015). En defensa de la ortología. BRAE (Boletín de la Real Academia Española), Tomo XCV, Cuaderno CCCXI, enero-junio, 179-190.

STAMPER, K. (2018). Palabra por palabra. Madrid. Capitán Swing.

STEINER, G. (2001). No hay lengua pequeña. El País, 27 de octubre.

VILAS, M. (2018). Ordesa. Madrid. Alfaguara. 